\title{
Red, Blue, and the Flu: Media Self-Selection and Partisan Gaps in Swine Flu Vaccinations
}

\section{Citation}

Baum, Matthew A. Red, Blue, and the Flu: Media Self-Selection and Partisan Gaps in Swine Flu Vaccinations. 2011. HKS Faculty Research Working Paper Series RWP11-010, John F. Kennedy School of Government, Harvard University

\section{Published Version}

http://web.hks.harvard.edu/publications/workingpapers/citation.aspx?Publd=7620

\section{Permanent link}

http://nrs.harvard.edu/urn-3:HUL.InstRepos:4696292

\section{Terms of Use}

This article was downloaded from Harvard University's DASH repository, and is made available under the terms and conditions applicable to Other Posted Material, as set forth at http:// nrs.harvard.edu/urn-3:HUL.InstRepos:dash.current.terms-of-use\#LAA

\section{Share Your Story}

The Harvard community has made this article openly available.

Please share how this access benefits you. Submit a story.

Accessibility 


\title{
Red, Blue, and the Flu: Media Self-Selection and Partisan Gaps in Swine Flu Vaccinations Faculty Research Working Paper Series
}

\author{
Matthew A. Baum
}

Harvard Kennedy School

\section{January 2011 RWP11-010}

The views expressed in the HKS Faculty Research Working Paper Series are those of the author(s) and do not necessarily reflect those of the John F. Kennedy School of Government or of Harvard University. Faculty Research Working Papers have not undergone formal review and approval. Such papers are included in this series to elicit feedback and to encourage debate on important public policy challenges. Copyright belongs to the author(s). Papers may be downloaded for personal use only. 


\title{
WORKING DRAFT --. COMMENTS WELCOME
}

\section{Red, Blue, and the Flu: Media Self-Selection and Partisan Gaps in Swine Flu Vaccinations}

This study assesses the relationship between political partisanship and attitudes and behavior with respect to the Swine Flu crisis of 2009 in general, and the U.S. mass vaccination program in particular. I argue that even seemingly non-partisan political issues like public health are increasingly characterized by partisan polarization in public attitudes, and that such polarization is in part attributable, at least in part, to the breakdown of the information commons that characterized the American mass media from roughly the 1950s until the early 1990s. In its place has arisen an increasingly fragmented and niche-oriented media marketplace in which individuals are better able to limit their information exposure to attitudes and opinions that reinforce, rather than challenge, their preexisting beliefs. I test my argument against a variety of data sources, including opinion surveys and state level Swine Flu vaccination rate data.

\section{Matthew A. Baum}

Marvin Kalb Professor of Global Communications and Professor of Public Policy

\author{
Harvard Kennedy School \\ matthew_baum@harvard.edu
}

January 25, 2011 
On September 30, 2009, as the Federal Government's efforts to persuade Americans to vaccinate themselves and their families against the Swine Flu were moving into high gear, conservative Fox News commentator Glen Beck informed his roughly 3 million viewers that, with respect the vaccine, "you don't know if this is going to cause neurological damage like it did in the 1970s," adding that he would do "the exact opposite" of what the federal government recommended, and might even attend a swine flu party in order to deliberately infect himself before the virus could mutate (LA Times 2009). A week later, on October $7^{\text {th }}$, conservative commentator, Rush Limbaugh told his radio audience - estimated at around 20 million listeners per week ${ }^{1}$ (Boehlert 2009) -- "I am not going to take it [the H1N1 vaccine], precisely because you are now telling me I must...I don't want to take your vaccine. I don't get flu shots. He added if "you have some idiot government official demanding, telling me I must take this vaccine, I'll never take it."

Taking a different tack, two Republican House Members - both doctors - raised objections to the pandemic funding included in a defense supplemental bill. Rep. Phil Gingrey (R-GA) commented, “We can't let all of our spending and our reaction be media-driven in responding to a panic so that we don't get Katrina-ed. ... It's important because what we are talking about as we discuss the appropriateness of spending $\$ 2$ billion to produce a vaccine that may never be used - that is a very important decision that our country has to make." Rep. Paul Broun (R-GA) added, "I don't think we need to spend $\$ 1.5$ billion on flu vaccine when ... the research shows that it's not going to be very virulent. ... We are stealing our grandchildren's future by borrowing and spending. ... This hysteria over the flu is driving the media, and it's

\footnotetext{
${ }^{1}$ Estimates of Limbaugh's audience magnitude vary from 2 to 50 million listeners per week (Boehlert 2009). Pew's Project for Excellence in Journalism rates his audience in Spring 2009 at about 15 million (www.stateofthemedia.org), compared to 14 million for Sean Hannity.
} 
driving the administration, driving the leadership here. We've got to stop that." More recently, Fox News business commentator David Asman expressed skepticism regarding the safety of the swine flu vaccine, and criticized the government for having exaggerated the threat (Media Matters 2010).

Though much of the criticism of the H1N1 vaccine and the government's response to the emergence of the virus came from the right, such concerns also appeared on the other end of the political spectrum. Notably, liberal talk show host Bill Maher Tweeted "people who get flu shots are idiots" and commented, in an interview with former Republican Senate Majority Leader and heart surgeon Bill Frist, "Why would you let them [the government] be the ones to stick a disease into your arm? I would never get a swine flu vaccine or any vaccine. I don't trust the government, especially with my health" (Parker-Pope 2009).

Perhaps not surprisingly, given the skepticism voiced by prominent politicians and commentators, combined with pre-existing skepticism about vaccination and immunization programs in general, many Americans - roughly half according to an October 2009 Pew Center survey - indicated that they did not plan to seek the H1N1 vaccine. Such figures worried public health officials who feared that the H1N1 virus could unleash a potentially devastating pandemic. A somewhat less well-known, but potentially even more troubling, pattern emerged in the same survey: Democrats were nearly 50\% more likely than Republicans (60 vs. $41 \%$ ) to indicate that they would take the vaccine (Schlesinger 2009).

What accounts for this stark partisan gap over a seemingly non-partisan topic? And does it hold potentially broader public health implications? In assessing the first question, the most obvious proximate explanation is that Republican partisans were merely responding to trusted (i.e., conservative and Republican) opinion leaders, who voiced greater skepticism of the vaccine 
(and of the seriousness of the threat in general) than their Democratic counterparts, as the opening anecdotes suggest.

This, of course, begs the question of why Republican elites would be more skeptical than Democratic elites. Several potential explanations immediately come to mind. First, Republicans tend to be more skeptical than Democrats of proactive government intervention in public life. The Obama Administration's push to promote near universal H1N1 vaccinations constituted a major government intervention in the private lives of citizens. Second, the messenger in this case - the Obama Administration - was more credible, all else equal, to Democrats than Republicans, simply by virtue of its partisan affiliation, while for the same reason skeptical Republican elites were more credible to Republican partisans. Third, greater Republican skepticism of international institutions, like the World Health Organization, further weakened the credibility of the pro-vaccination message to Republicans, relative to Democrats, who tend to be more trusting of global institutions (Page and Bouton 2006, Holsti 2004, Baum and Nau 2009).

Finally, Republicans and Democrats increasingly expose themselves to distinct information streams via the new media. The streams favored by Republicans, such as the Fox News Channel on cable, as well as conservative talk radio and Internet sites, may have been more critical of the swine flu vaccination program -- due to the first three explanations noted above -- than their liberal analogs preferred by Democrats. Such a pattern could, in turn, shape vaccination patterns in ways that hold profound implications for public policy and public health.

In this paper I assess the relationship between political partisanship and attitudes and behavior with respect to the Swine Flu crisis of 2009 in general, and the U.S. mass vaccination program in particular. I argue that even seemingly non-partisan political issues like public health 
are increasingly characterized by partisan polarization in public attitudes, and that such polarization is in part attributable to the breakdown of the information commons that characterized the American mass media from roughly the 1950s until the early 1990s. In its place has arisen an increasingly fragmented and niche-oriented media marketplace in which individuals are better able to limit their information exposure to attitudes and opinions that reinforce, rather than challenge, their preexisting beliefs.

I begin, in the next section, by reviewing the changing media landscape over the past several decades. I then relate the patterns to polarization in partisan political attitudes and behavior with respect to the Swine Flu in general, and the vaccination program in particular.

\section{The Changing Media Marketplace}

The decline of the traditional news media since the early 1990s is well documented and widely reported (Baum and Kernell 1999 \& 2007, Hamilton 2003, Baum 2003). The combined ratings for the evening newscasts of the "big three" broadcast networks (ABC, CBS, and NBC) have fallen from about 52 million viewers in 1980 to 22.3 million in 2009 (Pew 2010). Indeed, according to a 2008 survey (Pew Center 2008), the percent of Americans indicating that they regularly watch cable news now exceeds the percentage regularly watching network news (by 39 to $29 \%$ ).

Not only has the overall audience for network news declined dramatically, but the demographics of network news viewers have also shifted starkly. Where the typical network news viewer was once comparable to the median television viewer (after all, the networks enjoyed an oligopoloy from the 1950s to the 1980s), by 2008 the network audience was notably older (with a median age of 61.3 (Pew 2009) and, according to the Pew Center (2008), composed 
of more than twice as many Democrats as Republicans (45 vs. 22\% “regular" viewers).

The so-called new media, by which I refer primarily to cable news channels and the Internet, but also to political talk radio, differ in important ways from their traditional media cousins. Most notably, nearly all such outlets self-consciously seek to appeal to relatively narrow, and hence more loyal niches of the public. Rather than seeking to be all things to all people - as the major networks did during their heyday - new media outlets try to provide a product that more closely fits the preferences of a particular subset of the public.

In news and politics, the primary dimension upon which new media outlets have sought to differentiate themselves is ideology. Most notably, in 2010 there are prominent cable news channels aimed primarily at liberals (MSNBC), conservatives (Fox), and moderates (CNN). Similarly, on the Internet, the political blogosphere is dominated by ideologically narrow websites like Huffingtonpost.com on the left and Michellemalkin.com on the right. Political talk radio, in turn, is dominated by conservative voices like Beck, Hannity and Limbaugh, though there are some liberal niches, such as a program hosted by MSNBC analyst Ed Schultz. As the range of options available to consumers seeking political information has expanded, making available media environments that closely match their personal political preferences, audiences have increasingly availed themselves of the opportunity to self-select into ideologically friendly political news environments.

\section{Cable News}

Figure 1 shows the trend, from 2000 to 2008-09 in the partisan make-up of audiences for CNN, Fox, and MSNBC. These data are derived from pooled national surveys conducted by a market research firm (Scarborough), representing over 100,000 interviews for each period 
included in the graphic (Kernell and Rice 2010, Feltus 2009).

[Figure 1 here]

The curves in Figure 1 indicate that in 2000, the audiences for all three networks consisted of fairly similar proportions of Democrats and Republicans. The partisan gaps for viewers of CNN, Fox, and MSNBC were 4, 8, and 2 percentage points, respectively. By 2008-09, these gaps had expanded dramatically, to 30, 20, and 27 points, for CNN, Fox, and MSNBC, respectively. While it is certainly the case that some partisan overlap remains (Feltus 2009, Prior 2007, Kernell and Rice 2010, Gentzkow and Shapiro 2010) -- these data clearly suggest a fairly strong tendency toward partisan filtering on cable news. ${ }^{2}$

\section{Internet}

If niche programming has emerged as an important competitive strategy for television news, it is arguably the most consequential such strategy on the Internet. Research (Hindman 2007) has shown that a stunningly small number of political news-oriented outlets dominate news and public affairs traffic on the web. While some of the most heavily trafficked sites - such as CNN.com, MSNBC.com, and Yahoo News -- remain predominantly audience aggregators rather than disaggregators -- and collectively make up $27 \%$ of the top news sites (Pew 2009) -the political blogosphere functions primarily as an arena for partisan and ideological selfselection.

There are a variety of well-documented digital divides online, including by age, gender, race, and socio-economic status. Some - particularly gender and race -- have receded somewhat in recent years. In each case, the net effect is that some Americans are systematically more likely

${ }^{2}$ For additional data on partisan filtering of cable news audiences, see Baum (forthcoming). 
than others to rely upon the Internet for political news. Many of these divides are exogenous to the preferences and policies of individual Internet outlets. However, political ideology remains a key proactive filter that political news websites in general, and blogs in particular, frequently employ in seeking to build a loyal niche audience.

Along these lines, Baum and Groeling $(2008,2010)$ report that left-leaning political blogs, like DailyKos.com are disproportionately likely to cover news that favors Democrats over Republicans, while right-leaning blogs, like FreeRepublic.com are disproportionately likely to feature news favorable to Republicans over Democrats. Perhaps not surprisingly, given the ideological and partisan slant on political blogs, users of these sites are, on average, more likely than typical Americans to prefer news that reinforces their pre-existing preferences, more likely to discuss political news with family and friends (Baum and Groeling 2008) and, as shown in Figure $2,{ }^{3}$ more ideologically extreme.

\section{[Figure 2 here]}

Not surprisingly, the audiences for such outlets are highly skewed based on party affiliation. For instance, according to an April 2007 Nielsen report (All 2007), 77\% of HuffingtonPost.com readers were registered Democrats, and only 3.8\% were registered Republicans. While, as with cable news, some Internet consumers seek out news from across the ideological spectrum -- and some evidence (Gentzkow and Shapiro 2010) suggests they do so to a greater extent on the Internet than on cable - the Internet is nonetheless a particularly

\footnotetext{
${ }^{3}$ Source: Cooperative Campaign Analysis Project survey (CCAP 2008). In Figure 2, $0=$ moderate, $1=$ liberal or conservative, and $2=$ very liberal or very conservative (Source: CCAP 2008).
} 
amenable environment for ideological self-selection, and the aforementioned evidence from political blogs suggests that many politically oriented news consumers engage in such selfimposed ideological segregation. ${ }^{4}$

While the audience for political news on the Internet does not yet match that for television news (Baum and Groeling 2008), it is growing rapidly and is by no means trivial. For instance, according to an October 2010 comScore.com press release, in September 2008 the total number of unique visitors to the top 15 political blog sites was approximately 206 million. This represents about a $10 \%$ increase over the prior year. According to Pew Center data, in turn, in $201041 \%$ of respondents identified the Internet as their primary source of news, compared to $66 \%$ who identified Television. This represents the smallest television advantage ever recorded in Pew Center surveys. According to the same data, among Americans under age 30, the Internet is now the predominant source of news, beating out television by 13 percentage points (65 to 52\%) (Pew 2011).

\section{Political Talk Radio}

In one sense, political talk radio is anything but "new." Indeed, the tradition of populist radio dates back to Father Charles Caughlin who, during the Great Depression, railed against everything from Franklin Roosevelt and the New Deal, to racial and ethnic

\footnotetext{
${ }^{4}$ Along these lines, Baum and Groeling (2009) report evidence that some ideological news blogs cover the "other side" primarily to set the stage for making their own political argument, in effect using "opposition" political blogs as strawmen. It seems likely that at least some politically sophisticated Internet news consumers are similarly motivated when "crossing over" to ideologically hostile news sources.
} 
minorities and the influence of Jews. Hence, it is something of an awkward fit in the category of "new media." That said, talk radio in many respects predates other forms of media in targeting niche audiences in general, and political niche audiences in particular. Hence, it warrants at least a brief mention here.

According to Pew's stateofthemedia.org website, 12 of the 15 most popular talk radio hosts in Fall 2009 were conservative, and none were liberal. Indeed, the most popular liberal talk show host, Ed Schultz, attracted roughly 2.5 million listeners per day in 2009, down from 3 million in 2008. This represents roughly $1 / 6^{\text {th }}$ of the audience magnitude of conservative talkers Rush Limbaugh or Sean Hannity. This suggests that despite prominent liberal attempts to crack into the medium - most notably by the Air America Radio Network, which declared bankruptcy and ceased broadcasting in 2010 -- political talk radio remains largely a medium for conservative populism in the tradition of Father Caughlin.

\section{Back to the Future?}

Though in some ways unique, the current period is by no means the first time in American politics that partisan media have played an important role in public policy debates. Rather, viewed in a broader context, overwhelmingly nonpartisan journalism, as we saw in roughly the first four decades following World War II, appears to have been an historical anomaly.

To better understand the implications of our increasingly polarized information environment, it is helpful to consider the partisan press of the nineteenth and early twentieth centuries. In that era, citizens who wanted an accurate picture of the political landscape could read multiple newspapers with differing partisan loyalties in order to triangulate on the "truth" 
(Schudson 1981, Baum and Groeling 2010). ${ }^{5}$ Such a strategy could offset to some extent any potentially harmful effects of partisan-oriented media. Yet the question remains as to whether typical citizens in the contemporary period, faced with far more varied alternatives, are likely to embrace a triangulation approach to news consumption. The present differs from the past in numerous important respects, not least of which is the explosion in the twenty-first century of entertainment mass media and other competitors for scarce public attention.

While it may be the case that politically attentive Americans in the twenty-first century are proportionately similar in number to their counterparts in prior news eras, a far larger portion of the contemporary population enjoys and exercises the franchise than was the case in the nineteenth-century. Moreover, the ability of party organizations to reliably direct the voting of their members has declined with the death of party machines and the waning influence of state party bosses. Consequently, the breadth of consensus necessary to forge a bipartisan accord is far greater in the twenty-first century, and modern communication and polling technology allows nervous politicians to sense precisely when that consensus is eroding. Of course, gaining consent first requires capturing public attention, and even politically attentive citizens are unlikely to be able to attend to all of the competing messages in the modern media environment.

Not only is it possible to consume nearly limitless political news from virtually any ideological perspective, it is also possible to consume equally limitless entertainment media, while rarely if ever encountering politics (Prior 2007). This raises the opportunity costs for typical consumers of seeking out alternative political perspectives. Survey evidence suggests that

\footnotetext{
${ }^{5}$ For example, in their famous "Middletown" study of what they regarded as a typical American city in the 1920s, Robert and Helen Lynd $(1929,471)$ found that "The local morning paper distributes 8,851 copies to the 9,200 homes of the city, and the afternoon paper 6,715, plus at least half of an additional 785 sold on the street and news-stand. In addition, the circulation of out-of-town-papers . . . now totals 1200 to 1500 a day."
} 
substantial portions of the public also appear to lack the motive to do so. Not surprisingly, these same data indicate that as the strength of an individual's political ideology increases, so too does that individual's preference for news that reinforces her pre-existing beliefs (recall Figure 2) (Baum and Groeling 2010).

If the new media environment is characterized more by reinforcement seeking than by triangulation, forging and sustaining bipartisan consensus around even seemingly non-partisan issues like flu vaccination programs will likely prove a daunting and perhaps all but insurmountable task for future leaders. Evidence of this dilemma emerges in public reactions to the 2003 U.S. invasion and subsequent occupation of Iraq, a conflict that produced the greatest partisan divide ever recorded in scientific polling, both in terms of support for a U.S. military conflict and in terms of overall presidential approval (Jacobson 2006). Scholars (e.g., Kull, Ramsey and Lewis 2003, Della Vigna and Kaplan 2003, Jacobson 2007) continue to debate the media's role in sharpening, if not altogether producing, the partisan gulf in evaluations of the president and the Iraq War. Jacobson (2007), for instance, speculates that a combination of differences in content and partisan self-selection into friendly news environments -- such as Fox for Republicans and conservatives, PBS, MSNBC, and CNN for Democrats and liberals, and network news for independents and moderates -- may have contributed to partisan differences in perceptions of the war and the president leading it.

As the prior discussion attests, self-selection, a concept dating back to Campbell and colleagues' (1960) theory of minimalism, may well be sharpening partisan polarization, and this phenomenon seems likely to expand in the future. However, there exists a second, perhaps complementary, culprit: ideologically driven credibility assessments. In other words, contemporary citizens possess, arguably to a greater extent than their predecessors, the means to 
engage in a multipronged dissonance-avoidance strategy. Selective exposure, or avoiding dissonant information altogether, presumably represents the first such prong. However, even when this first defense mechanism fails and individuals are exposed to ideologically hostile news, they increasingly possess the means -- by assigning ideological reputations to individual sources and media outlets -- to systematically discount it. In other words, consumers appear also to selectively accept or reject information to which they are exposed based on its perceived credibility (Baum and Groeling 2010). Credibility assessments in turn depend on the perceived ideological leaning of the outlet presenting the information, as well as on the content of the information itself (e.g., its perceived costliness). The combined influence of selective exposure and acceptance appears, at least in the cases of Iraq and overall assessments of President Bush's job performance, to have contributed substantially to then historically unprecedented levels of partisan polarization during President Bush's second term and more recently in President Barack Obama's second year in office. This leads consumers toward what I term Self-Segregated Information Streams. This, in turn, contributes to the progressive erosion of what might be thought of as the informational commons; that is, the common civic (virtual) space, occupied for roughly four decades by network television nightly newscasts, where a broad cross-section of Americans gathered to learn about the events of the day.

But to what extent to the patterns identified herein, and resulting Self-Segregated Information Streams, shape public perceptions of, and responses to, the 2009 Swine Flu pandemic and subsequent vaccination program? It is to this question that I now turn.

\section{Partisan Polarization and the Flu}

When news of the H1N1 virus, commonly known as Swine Flu, first hit the U.S. media, 
Americans across the political spectrum focused intensely on the issue. As shown in Figure 3, in the first Pew Center News Interest Index survey to include a question on the Swine Flu conducted in late April 2009 -- 91\% of Republicans, 89\% of Democrats, and 87\% of Independents indicated that they were following the issue "very" or "fairly" closely. These data suggest that at least initially there was no partisan gap in attention to the Swine Flu story.

[Figure 3 here]

This near-universal interest rapidly dissolved; within a week, a second Pew survey found Democrats 12 percentage points more likely than Republicans to report following the flu story very or fairly closely, a gap that recurred in 13 of 15 Pew Center surveys that included the question between May and December 2009. The gap peaked at 18 percentage points in November 2009. In that same November survey, Republicans were nearly 2.5 times more likely (49 vs. $21 \%$ ) to believe that news reports were overstating the danger of the Swine Flu. This partisan gap further expands - from 28 to 34 percentage points ( 39 vs. $5 \%$ ) -- when we limit the sample to respondents who indicated that they were following the Swine Flu story very closely.

Returning to the October survey cited at the outset of the study, which found Democrats far more likely than Republican to indicate that they would get the H1N1 vaccine if available, nearly twice as many Democrats as Republicans ( 82 vs. $49 \%$ ) expressed confidence in the government's ability to deal with the Swine Flu. Moreover, nearly twice as many Republicans as Democrats (18 vs. 10\%) indicated (in an open-ended question) that they would not get the vaccine because it was too risky or inadequately tested. Among Republicans who report following the swine flu issue more closely than any of the other issues in the news included in the survey, the percentage indicating that they would not get the flu vaccine because it was too 
risky swells to $26 \%$. The corresponding percentage among Democrats varies hardly at all as attention to the Swine Flu issue rises.

Interestingly, these percentages far exceed the roughly 4 and 5\% of Republicans and Democrats, respectively, who indicated that they would not get the vaccine because the Swine Flu risk had been exaggerated. These percentages remain nearly constant for Democrats or Republicans regardless of their level of attention to the issue. This latter justification seems on its face more clearly attributable a general distrust of the government, which, as noted, was far more prevalent among Republicans, presumably due to the presence of a polarizing Democrat in the White House combined with generally lower levels of faith in government among Republicans.

That said, in a May 2009 Gallup poll, the correlations between approval of President Obama's job performance and expressing an intent to get the H1N1 vaccine when available, on the one hand, and believing the media were exaggerating the danger associated with the Swine Flu, on the other, were only about .10 and -.02, respectively, among Republicans (compared to .01 and -.06 , respectively, among Democrats). The correlations among Republicans change only modestly when we limit the sample to self-described conservative Republicans (.09 and .03 , respectively). This suggests that while general Republican or conservative distrust of government, or of a Democratic president, almost certainly accounts for part of these differences, it is insufficient to fully account for these patterns.

Why then would those respondents most attentive to the Swine Flu story be most likely to diverge in their opinions about it, with nearly all highly attentive Democrats believing the story was either being covered appropriately or that the media were understating the danger, while nearly $40 \%$ of attentive Republicans held the opposing view? Why, in turn, were Republicans 
less trusting of the government's capacity to deal with the flue epidemic and more likely to worry that the vaccine itself was dangerous, especially if they were paying close attention to the issue, while variations in attentiveness had almost no effect on Democrats? In the next section, I argue that the explanation lies, at least in part, in the different information streams to which Republicans and Democrats exposed themselves, and from which they received starkly varying messages - both in terms of quantity and valence - on the Swine Flu in general, and the vaccination program in particular.

\section{News Consumption and Attitudes Toward the Swine Flu}

I have been unable to identify any surveys asking respondents in detail their sources of news about the Swine Flu and vaccine. However, several surveys include questions on attitudes regarding $\mathrm{H} 1 \mathrm{~N} 1$ or the vaccine and general categories of news sources about the flu (e.g., cable, internet, national TV, etc.). These data allow some suggestive, albeit far from definitive, tests of the hypothesis that the different information streams preferred by Democrats and Republicans in the new media help account for the partisan gap in attitudes regarding the pandemic.

The previously mentioned May 2009 Pew Center survey asked respondents how worried they were that they or a family member would be exposed to the flu. Responses ranged from "not worried at all" to "very worried." The survey included the aforementioned question asking about respondents' primary sources of news about the Swine Flu. My hypothesis anticipates greater partisan polarization in worry over the flu among new media consumers than among consumers of traditional news sources, where all viewers are exposed to more similar information stream.

To test this prediction, I divided the media outlets included in the question into two categories, with cable TV, Internet, and radio counted as "new media" and Local TV news, 
national network TV news, morning TV news shows, and newspapers counted as traditional news sources. A ttest indicates that there is no statistically significant difference in the likelihood that Democrats or Republicans who rely primarily on traditional news sources will be "very" or "somewhat" worried about the flu. Conversely, among respondents who indicated that they relied primarily on new media sources Democrats were 11 percentage points more likely than Republicans to express worry over the Swine Flu (.40 vs. .29). This partisan gap is statistically significant at $p<.02$. If we exclude radio from the new media category, which is then limited to cable and the Internet, the gap expands to 13 percentage points (.41 vs. .28, $p<.02$ ).

Two additional sets of ttests offer further evidence that media consumption is linked to attitudes regarding the dangers of Swine Flu. The first compares whether Democrats and Republicans who do or do not report relying on new media sources for news about the flu believe the media are offering too much vs. too little Swine-Flu-related news. Among traditional news-oriented respondents, Democrats were a little more than 13 percentage points less likely than Republicans $(.268$ vs. $.402, p<.03)$ to believe the media were offering too much swine flu news. The partisan gap is far larger ( .24 percentage points) among new media consumers (.37 v. .61, $<$ <.001). The results are comparable when we substitute a question asking respondents how they would rate the quality of news coverage of swine flu, with Republicans again being significantly more likely than Democrats to rate press coverage poorly, particularly if they relied on new media sources for news about the pandemic. Fully 83 and 77 percent of Democratic traditional and new media reliant consumers, respectively, rated press coverage positively, compared to only .61 and .48 percent of Republicans. The difference between new and traditional news consumers is insignificant among Democrats, while among Republicans the gap is significant at $p<.03$. 
Attitudes regarding the quality of media coverage of Swine Flu, in turn, influence the extent of respondents' concern about it. For instance, among Republicans who rate press coverage of the flu positively, there is no significant difference in concern over the flu between those who report relying on traditional vs. new media sources for flu-related information (.34 vs. .40). However, among Republicans who rate press coverage of the flu negatively, a large (21 percentage point, $p<.01$ ) gap emerges between those who report relying on new vs. traditional media sources for flue-related news, with new media consumers reporting far lower levels of concern about the flu. Nearly all of that gap, in turn, results from a 23 percentage point drop among new-media-reliant consumers as they move from positive to negative attitudes regarding the quality of press coverage of the flu story.

In sharp contrast, no significant gaps emerge among Democrats. This, again, seems likely attributable to the propensity of Democrats to seek out news sources via news media that are relatively sympathetic to the Administration's representation of the Swine Flu pandemic as a major emergency. Moreover, traditional news sources (like network newscasts) are, all else equal, highly likely to highlight the Administration's perspective in a crisis, due to its status as the most authoritative information source, especially early in the crisis, as was the case at time of this survey (Baum and Groeling 2008 \& 2010).

Finally, it is worth noting that among both groups of partisans who rate press coverage positively, relying on new media sources for flu news is associated with higher levels of concern, while among those who rate coverage poorly, reliance on new media sources is associated with lower levels of concern about the flu (though these latter differences are not statistically significant, and hence must be interpreted with caution). 
These results suggest that when given the opportunity to self-select into ideologically "friendly" media environments - as is far more likely in the new than in the traditional media partisans are likely to diverge fairly starkly in their attitudes toward the pandemic. However, when confronted with a common information stream - as in the traditional news media - they respond by converging in their attitudes, regardless of partisanship. Moreover, the fact that attitudes regarding press coverage of the Swine Flu story appear closely correlated with news source selection, which in turn appears closely related to concern over the flu, with each relationship heavily mediated by party affiliation, represents further suggestive evidence in favor of the Self-segregated Information Stream hypothesis.

Unfortunately, data limitations in this survey make it impossible to rule out the possibility that differences in the internal characteristics - such as ideological extremeness -- of new vs. traditional news viewing Republicans or Democrats may account for these patterns. After all, as I have already shown (recall Figure 3), strength of ideology is positively associated with preferring news that reinforces one's preexisting beliefs. So it is doubtless the case that stronger partisans are more prone to self-select into ideologically "friendly" information environments than are weaker partisans, which in turn seems likely to steer them toward new media outlets, which tend to be more amenable to such self-selection. That said, it is worth noting that these results do not appear to derive from differences in overall interest in or attention to the flu across new vs. traditional news consumers. There is no statistically significant difference in the likelihood of having followed the Swine Flu story most closely among the six major news items included in the survey for either Democrats or Republicans who reported relying primarily on new vs. traditional news media sources for flu-related news.

If it is the case that respondents who prefer new media sources for news about the swine 
flu do so because they are, on average, more partisan or more ideologically extreme - with new media-oriented Republicans being more conservative and new media-oriented Democrats more liberal than their traditional-news-consuming counterparts -- then such a preference might also predict similar differences in attention to other news stories, particularly those with clear partisan implications. To test this possibility, I conducted two ttests: one employing two non-overtly partisan news issues issues (the financial problems of the US auto industry and the state of the economy) and one employing two more directly partisan issues (President Obama's first 100 days in office and to Senator Arlen Spector's switch from the Republican to the Democratic Party). For the less-partisan issues, I found, as expected, comparably small and insignificant differences for both parties. That is, preferring new over traditional media sources for news about the swine flu does not predict differences in attention to the financial woes of the American auto industry or the economy, regardless of party.

For the more overtly partisan issues, Republican new media consumers reported having followed the stories $6 \%$ more closely (2.76 vs. 2.60 on the $1-4$ scale), on average, than their traditional-news-viewing counterparts. This gap, though nearly significant, is substantively quite small. This, in combination with the fact that virtually no gap at all emerged among Democrats, suggests that a preference for new media sources for swine flu news - here employed as a possible indicator of ex ante strength of partisanship or ideology - does not appear clearly associated with the decision to consume new vs. traditional news media.

Somewhat more direct evidence in this regard is available from a May/June 2009 Pew Global Values Survey, which included several questions with clear ideological implications, along with questions about the Swine Flu and news sources. In this instance, the survey asked whether respondents primary source of national or international news was television, radio, 
Internet, newspapers or magazines. Because television is not divided into cable vs. broadcast, while the "radio" category is obviously not necessarily limited to political talk radio, the status of these outlets as new vs. traditional media is ambiguous. However, I find substantively tiny and statistically insignificant differences in the self-reported ideological extremeness ${ }^{6}$ of respondents who rely on television, radio or the Internet for national or international news.

That said, a ttest on the extent to which respondents indicate they are worried that either they or a family member will be exposed to Swine Flu ${ }^{7}$, finds that Democrats who primarily rely on the Internet or TV for national or international news are significantly more worried about Swine Flu than their Republican counterparts, even when I exclude strong ideologues (that is, respondents describing themselves as "very conservative" or "very liberal"). The partisan gaps, with strong ideologues excluded, are $.39(p<.02)$ and $.32(p<.001)$ points on the $1-4$ scale, or .35 and .29 standard deviations for Internet and TV news consumers, respectively. The corresponding partisan gap for respondents who indicated that they rely primarily on newspapers or magazines (more traditional sources with less opportunity for ideologically-based selfselection) for their news was far smaller (.14, or .13 standard deviations) and statistically insignificant, again with strong ideologues excluded. ${ }^{8}$ The results differ only modestly when ideologues are included in the ttests. Similar patterns emerge if I exclude respondents who indicated in a separate question that they had either "no confidence at all" (in one test) or "a lot

\footnotetext{
${ }^{6}$ This is based on a question asking respondents about their political ideology, recoded to a 0-3 scale, where $0=$ moderate or "don't know", $1=$ liberal or conservative, and $2=$ very liberal or very conservative.

${ }^{7}$ Response options were: $3=$ very worried, $2=$ somewhat worried, $1=$ not too worried, or $0=$ not at all worried. Those who indicated they were "exposed already" were excluded, while "don't know" responses were recoded to the center of the scale (1.5).

${ }^{8}$ Too few respondents identified radio as their primary news source to include it as a separate new media category. For the same reason I combine newspaper- and magazine-oriented respondents, though the results are similar if I isolate the newspaper category (too few respondents chose magazines to allow a separate ttest of that category).
} 
of confidence" (in a second test) that President Barack Obama would "do the right thing regarding world affairs," or if I exclude respondents who indicated, in another question, that they did not approve of President Obama's international policies. ${ }^{9}$ This suggests that, while ex ante ideological extremeness or attitudes toward President Obama, and the effects of those attitudes on media outlet choice, almost certainly influence the observed partisan gaps, they cannot, by themselves, fully account for them. Seemingly, the information to which respondents expose themselves in these various media also matters.

One final test offers additional evidence substantiating this assertion. A 23-26 October 2009 Pew Center survey asked respondents which news stories they were following most closely as well as their "regular" sources of news. The question listed six specific news story options as well as an "other story" category. Response options for the latter question, that in this survey (unlike the others) were not mutually exclusive, included local TV news, national network TV news, MSNBC, FOX, CNN, radio news, newspapers, or the Internet. I conducted a set of ttests to determine whether self-identified conservative Republicans differed in their propensity to identify Swine Flu as the issue they had followed most closely in the news during the previous week, depending on whether or not they identified Fox News as a regular source of news. I then compared the results for Swine Flu with those for several other news stories identified in the survey, including the health care debate, the state of the national economy, efforts by the Obama Administration to place limits on executive pay for companies that took bailout funds, the war in Afghanistan, and political instability in Pakistan.

Beginning with the "other" news stories, the results indicate that there is no statistically

\footnotetext{
${ }^{9}$ In this instance, too few respondents (29\% and $6 \%$ of Democrats) expressed disapproval to isolate that category for a separate ttest of partisan differences.
} 
significant attention difference between conservative Republican Fox viewers and their non-Foxviewing counterparts with respect to the economy, executive pay, or Afghanistan. Too few conservative Republicans mentioned Pakistan to determine whether or not viewers and nonviewers differed meaningfully. Finally, regular Fox viewers were 18 percentage points more likely than non-regular-viewers to cite the health care debate as the issue they had followed most closely in the news $(p=.05)$.

The results for Swine Flu are far starker. Conservative Republicans who cited Fox News as a regular news source were more than twice as likely as those that did not mention Fox to name Swine Flu and the vaccine as the issue they had followed most closely (.40 vs. .18, $p<.003)$. Equally important, this relationship is unique to Fox News, at least in its magnitude and significance. No statistically relationships emerged for local TV news or newspapers. However, conservative Republicans who cited national network news as a regular news source were 10 percentage points more likely than their counterparts who did not to name Swine Flu and the vaccine issue as the story they had followed most closely the prior week (.30 vs. .20, $p<.10)$.

Several of the other "new" media outlets - including CNN and radio news -- were also associated with reduced attention to Swine Flu. Regular radio news consumers were about 7 percentage points less likely than non-radio-news-consumers to indicate that they had followed the Swine Flu/vaccine issue most closely, though this effect is not statistically significant. The corresponding drop in attention for regular $\mathrm{CNN}$ viewers is about 12 percentage points ( .28 vs. .16, $p<.10$ ). If I limit the sample to respondents who identified themselves as "very conservative," then regular Internet consumption is associated with a 7 percentage point, albeit statistically insignificant $(p<.19)$ decline in the likelihood of having followed Swine Flu and its vaccine most closely of the issues in the news the prior week (.18 vs. .11). 
The fact that other new media did not produce attention effects vis-à-vis Swine Flu and the vaccine comparable in magnitude or significance to that associated with Fox likely stems from several factors, including (a) Fox's status as a particular focal point for conservative Republican news consumers, (b) in some instances, the specificity of Fox News relative to, say, "radio news" in the survey question, the latter of which presumably includes political talk radio, but also other less politically slanted fare, and, perhaps most important, (c) the fact that respondents were able to select as many of the outlets from the list as they liked. This means that some of the Fox consumers almost certainly also exposed themselves to other media, like national network news or local TV news, potentially offering somewhat different messages regarding the Swine Flu and the vaccine program.

In sharp contrast to the patterns for conservative Republicans, among self-described liberal Democrats no statistically significant differences between regular Fox viewers and nonviewers emerged for any of the news stories. The same pattern emerges among liberal Democrats across all the media outlets included in the survey, with the sole exception of local TV news. Liberal Democrats who regularly watch local TV news were 18 percentage points more likely (.34 vs. .16, $p<.05)$ than their counterparts who did not regularly watch to report following the Swine Flu/vaccine issue most closely. Presumably, the weaker relationships for liberal Democrats stem from the aforementioned higher ex ante levels of interest in the issue among Democrats and greater trust of the government officials and agencies talking about it. That said, when I limit the analysis to self-described "very liberal" respondents, the results strengthen considerably for national network news and MSNBC. In the former case, regular viewing of network news among very liberal respondents is associated with a 24 percentage point increase in the likelihood of having followed Swine Flu and its vaccine most closely during the prior 
week (.42 vs. .18, $p<.05)$. The corresponding increase among regular MSNBC viewers is 9 percentage points (.35 vs. .26). However, this latter relationship is statistically insignificant $(p<.25)$, presumably do to the fairly small number of regular MSNBC consumers included in the survey.

These results clearly suggest that regularly consuming Fox News had quite different effects on the attention of conservative Republicans to Swine Flu and the vaccine than with respect to any of the other policy issues on the national agenda, substantially reducing their interest in the issue. Other new media mostly exhibited similar, albeit weaker effects. In contrast, network news consumption produced the opposite effect, at least among especially conservative respondents. Fewer significant relationships emerged among liberal Democrats, regardless of their sources of news, though several outlets typically preferred by liberals were associated with positive attention effects among "very liberal" respondents..$^{10}$ Taken together, these patterns appear largely to supports the Self-segregated Information Stream hypothesis.

Thus far, we have seen suggestive evidence that the trend toward increasing self-selection by Americans into politically "friendly" news environments, especially in the new media (cable, Internet, political talk radio, and especially Fox News) may help account for the partisan gap in concern over the Swine Flue and in self-reported intent to seek the Swine Flu vaccine. Of course, survey questions regarding interest or "intent" are not equivalent to actual behavior. Hence, in the next section I investigate state-level data on swine flu vaccination rates to see whether the sorts of patterns identified in the survey data reflect actual behavior.

\footnotetext{
${ }^{10}$ While, in order to address the endogeneity concern raised earlier, I focused in this instance on "liberal Democrats" and "conservative Republicans," many of the patterns identified above, particularly with respect to Fox News, remain similar if I limit the analysis to liberals, conservatives, Democrats, or Republicans.
} 


\section{A Vaccination Gap?}

To investigate actual patterns of vaccinations for Swine Flu, and determine whether there is evidence that political partisanship influences vaccination rates in part due to the different information streams to which partisans expose themselves, I turn to state-level CDC data on H1N1 immunizations and deaths from Swine Flu. ${ }^{11}$ To account for partisan differences, I employ Gallup data on the on the gap in party affiliation in each state in 2008 , as well as on whether each state voted for Obama or McCain in 2008 (Jones 2009). The best-available proxy I was able to identify for the differing media streams consumed by residents of each state is a data set developed by Gentzkow and Shapiro (2010) on partisan bias in newspapers. Gentzkow and Shapiro rated 434 U.S. newspapers on a left-to-right ideological continuum, with the number of papers for an individual state ranging from 1 (in Wyoming, Arkansas, and Delaware) to 49 (in California). The mean number of newspapers-per-state is 8.5 with a standard deviation of 8.68 . The scale ranges from -.08 to .585 , with larger numbers representing more rightward slant. ${ }^{12}$ I also collected a variety of state-level demographic and political data, which I employ as control variables in my analyses. ${ }^{13}$

The survey analysis presented in the prior section suggests that Republicans are, all else equal, less concerned than Democrats about Swine Flu. The implication is that we would expect Republicans to be less likely to seek the H1N1 vaccine. At the state level, this

\footnotetext{
11 Data available at: http://maps.google.com/maps/ms?ie=UTF8\&hl=en\&msa=0\&msid=109496610648025582 $911.0004686892 \mathrm{fbefe} 515012 \& \mathrm{z}=3$ and www.flucount.org. I further verified data at http://en.wikipedia.org/wiki/2009_flu_pandemic_in_the_United_States.

${ }^{12}$ I am grateful to Matt Gentzkow for making these data available to me. See Gentzkow and Shapiro (2010) for a detailed explanation of the construction of the slant scale.

${ }^{13}$ Data available at: http://www.statehealthfacts.org/.
} 
should manifest itself in the form of higher per-capita infection rates and potentially also higher per-capita H1N1-related fatality levels in states with relatively higher proportions of registered Republicans-to-Democrats. Moreover, to the extent that differences in media coverage of the flu influenced consumers' levels of concern about it, and hence propensity to seek the vaccine, we would expect that, net of other likely causal factors, more rightleaning state media would be associated with lower per-capita H1N1 vaccine rates and perhaps also higher H1N1-related death rates.

As preliminary tests of these predictions, I begin with some simple correlations and ttests. The first such test reveals, consistent with my expectations, a highly significant .30 correlation between per-capita swine flu deaths and the partisan registration gap in 2008, indicating that as states become relatively more Republican, Swine Flu-related deaths rise. Turning to H1N1 vaccination rates for people over 6 months of age, these data indicate that in states with over a standard deviation above the mean pro-Republican tilts in party registration, residents were over $8 \%$ less likely to be vaccinated than their counterparts in states with over a standard deviation above the mean pro-Democratic party registration tilt (.247 vs. .329, $p<.03)$. This represents a fully 1.33 standard deviation difference in proportions of the population vaccinated against H1N1. A similar, albeit predictably somewhat less stark, pattern emerges if we compare states that voted for Obama in 2008 to those that voted for Republican candidate John McCain. Here the partisan vaccination gap is about 4 percentage points ( .22 vs. $.26, p<.02)$, or $2 / 3$ of a standard deviation on the vaccination scale.

These simple correlations suggest that there is indeed a fairly strong correlation at 
the state level between partisanship and H1N1 vaccination rates. However, it cannot rule out the possibility that demographic factors, such as poverty, might be the true causal factor. Nor do they address the potential influence of media exposure. To address these concerns, I turn to a multiple regression analysis. The dependent variable for this analysis is the percentage of state residents over 6 months of age that were vaccinated against H1N1 in 2009. The key causal variables are newspaper slant, the partisan registration gap, and whether a state voted for Obama in 2008.

Controls include the unemployment rate, the percent of the population that is African American, the percent of the population that is Hispanic, the per-capita number of swine flu cases in the state, as well as the ideological slant in rhetoric by the state's congressional delegation (as measured by Gentzkow and Shapiro 2010). Tables 1A and 1B present the results of 13 regressions. The first model excludes all but several basic controls (unemployment, race, number of H1N1 cases per capita, and the rhetorical slant of the state's congressional delegation). The second adds the partisan registration gap, and the third adds the voted for Obama dummy. The remaining models incrementally add a variety of socio-economic and demographic variables that could potentially account for variations in $\mathrm{H} 1 \mathrm{~N} 1$ vaccine rates. I include them incrementally due to the limited statistical leverage available in the data.

[Tables A1 and 1B here]

The results indicate that even after controlling for a variety of potential alternative causal factors, both the partisan registration gap and having voted for Obama in 2008 influence the percentage of a state's population immunized against H1N1. So too do many 
of the controls, including unemployment rates, race, flu vaccination rates and the rhetorical slant of the state's congressional delegation. In the first case, Model 2 indicates that each one percent increase in the pro-Democratic registration tilt is associated with about 7 percent increase in immunization rates $(p<.10)$. Model 3, in turn, indicates that states that voted for President Obama in 2008, in turn, had about 2.7 percent higher immunization rates than their counterparts who voted for Senator McCain ( $p<.10)$. Model 1, which presents the base model, represents the most basic test of the Self-segregated Information Stream hypothesis. The results here indicate that states with more conservative newspapers did indeed have lower immunization rates, even after accounting for alternative explanations. The coefficient on newspaper slant indicates that each one-point increase in rightward slant in a state's newspapers is associated with a .98 percent decrease in immunization rates.

It is important to reiterate that this effect is net of the ideological slant of the state's Congressional delegation, as well as of the socio-economic characteristics of the state. ${ }^{14}$ It is also net of the partisan registration gap, though the magnitude of the effect is slightly weaker when the latter variable is included in the model (with the coefficient declining from -.98 to -.76, while remaining significant at the .10 level). It is also largely unaffected when child immunization rates or adult flu vaccination rates are included as controls, and remains substantively large and statistically significant in every model, regardless of the

\footnotetext{
${ }^{14}$ In separate models (not shown), I tested additional socio-economic factors such as the percent of the state's population living in urban vs. rural communities, median state income, infant death rates, state spending on Medicaid and healthcare in general, per capita GDP, and population size. None significantly affected the H1N1 vaccination rate after the reported controls were included in the models. Hence, given my limited degrees of freedom, I excluded them from the reported results.
} 
socio-economic or demographic control included. This suggests that generalized skepticism of vaccinations do not fully account for reluctance to seek the H1N1 vaccine. The reason, presumably, is that the latter vaccine was more overtly politicized than seasonal flu vaccines or child immunizations.

Interestingly, when I replicated Tables $1 \mathrm{~A}$ and $1 \mathrm{~B}$ with childhood immunizations as the dependent variable (not shown), there is no significant effect of newspaper slant across all models. Replicating the same models with, as the dependent variable, the percent of adults receiving seasonal flu vaccines (also not shown), on the other hand, is significantly affected by newspaper slant in many, though not all models. In the latter set of models, the coefficients on newspaper slant are consistently smaller than they are in the Swine Flu immunization models. More important for my purposes, the coefficient on newspaper slant becomes small and insignificant when the partisan gap variable is included as a control. In other words, absent an explicit control for general partisan differences in attitudes regarding flue vaccines, newspaper slant served as a reasonably appropriate proxy. However, in the presence of a more direct control, it loses its predictive power. This suggests that in the case of the seasonal flu, while partisan differences in attitudes among Democrats and Republicans do appear to matter - most likely owing to general differences in levels of trust in government programs and pronouncements -- these differences do not appear to directly stem from differences in Self-Segregated Information Streams via mass media.

\section{Conclusion}

I began this study by highlight a potentially important puzzle: Republicans appeared 
in surveys to express far lower levels of intent to seek Swine Flu vaccines than their Democratic counterparts. While there are almost certainly multiple explanations for this partisan gap, I argued that one part of the explanation concerned the evolution of mass media toward greater consumer capacity to self-select into ideologically "friendly" news and information environments.

I tested several implications of what I termed the Self-Segregated Information Stream Hypothesis against several data sets. I first found strong partisan gaps in concern over the flu that appeared highly correlated with news consumption preferences. Most notably, Republicans who rely on new media in general, and Fox News in particular, for news about Swine Flu are substantially less concerned about the flu, less attentive to it, and more skeptical of press coverage of the flu than their counterparts who rely on traditional news sources, or Democrats regardless of news sources. In the latter case, Democrats are most likely encountering similar information streams both in self-selected new media contexts, where they can seek out pro-Administration information streams, and in the traditional news media, where Indexing Theory (Bennett 1990, Baum and Groeling 2010) anticipates that the Administration's voice will tend to dominate news coverage in a crisis, especially in its early stages.

While these survey data cannot rule out the possibility of reverse causality - that is, attitudes regarding the Swine Flu vaccine are "caused" by ideological preferences, which in turn "cause" media consumption choices -- several indirect tests suggested that this causal arrow is unlikely to fully account for the observed patterns (though it almost certainly contributes to them). 
Finally, an investigation of real world, state-level, vaccine data reveals that these attitudes expressed in surveys appear to be reflected in actual patterns of Swine Flu vaccinations. Here, while I could not distinguish new vs. traditional media exposure, I was able to demonstrate that the overall tone of newspaper coverage in a state, on a left-toright scale, strongly influences the percentage of the population seeking the H1N1 vaccine, even after accounting for a wide range of alternative potential explanations, ranging from a state's political orientation, to its demographics, to the socio-economic and ethnic profile of its population.

Because the evidence presented in this study is mostly suggestive, further research is necessary to more directly draw a linkage between Self-Segregated Information Streams and public health behavior in general, or Swine Flu vaccine rates, in particular. However, the evidence presented herein does strongly suggest that changes in the mass media environment hold potential profound implications for public health.

Current trends toward ever more consumer self-selection and increasingly sophisticated information filtering and media targeting of consumer preferences all appear to portend a trend toward greater audience fragmentation and hence continued shrinking of the Informational commons. For instance, it seems inevitable that news providers will increasingly apply the same filtering technologies that allow media content distributors like Netflix and iTunes to determine the types of movies or music a customer is likely to prefer, and suggest to them precisely that, to news and public affairs content. The end result may be what Cass Sunstein (2007) terms "cyberbalkanization," where the informational commons is largely supplanted by a "daily me" in which consumers 
encounter only the news and information they want, most of which tends to confirm rather than challenge their preexisting attitudes. Whether or not the informational commons disappears entirely, there is little question that technological innovations and shifts in audience behavior are changing the way citizens consume news, with content growing increasingly personalized and subject to individual preferences regarding what, when and where they entertain themselves or expose themselves to politically themed information.

Given the enormity and speed of the changes in this media marketplace, the potential consequences for democratic participation and the strategic landscape for politicians, the evolution of the communication environment within in which our politics are contested seems likely to play a central role in shaping the future course of American democracy. With respect to public health, to the extent that this Self-Segregated Information Stream process continues apace, the politicization of public health campaigns poses substantial risks to the efficacy of public health policy. It is therefore incumbent upon policymakers to strive to avoid such politicization to the greatest extent possible. Because many public health issues are not intrinsically partisan, it is easy to miss their potential for generating polarized attitudes and behaviors, a potential that politically oriented new media providers have strong commercial incentives to exploit. Failing to recognize the potential health consequences of polarized debates surrounding seemingly non-partisan issues like protecting against flu pandemics thus risks undermining their effectiveness. 


\section{REFERENCES}

All, David. 2007. “Is Yahoo!'s Online Debate Going to be Fair and Balanced?” techPresident Blog, April 26. techpresident.com/blog-entry/yahoo's-online-debate-going-be-fair-andbalanced.

Baum, Matthew A. 2003. Soft News Goes to War: Public Opinion and American Foreign Policy in the New Media Age. Princeton, NJ: Princeton University Press.

Baum, Matthew A. Forthcoming. Preaching to the Choir or Converting the Flock: Presidential Communication Strategies in the Age of Three Medias. In iPolitics, edited by Richard Fox and Jennifer M. Ramos, Cambridge: Cambridge University Press.

Baum, Matthew A., and Tim Groeling. 2008. "New Media and the Polarization of American Political Discourse." Political Communication 25 (4): 345-65.

Baum, Matthew A. and Tim Groeling. 2010. War Stories: The Causes and Consequences of Citizen Views of War. Princeton: Princeton University Press.

Baum, Matthew A. and Sam Kernell. 1999. "Has Cable Ended the Golden Age of Presidential Television?” American Political Science Review 93 (March): 1-16.

Baum, Matthew A. and Samuel Kernell. 2007. "How Cable Ended the Golden Age of Presidential Television: From 1969-2006." In The Principles and Practice of American Politics, edited by Samuel Kernell and Steven S. Smith. Washington D.C.: CQ Press.

Baum, Matthew A. and Henry Nau. 2009. "Foreign Policy Views and U.S. Standing in the World." Paper presented at the annual meeting of the American Political Science Association, Toronto, Canada, September 3-6.

Bennett, W. Lance. 1990. "Toward a Theory of Press-State Relations in the United States." Journal of Communication 40 (2): 103-125. 
Boehlert, Eric. 2009. "Why Don’t We Just Pretend Rush Limbaugh Has 50 Million Viewers?" Media Matters for America. March 9. mediamatters.org/columns/200903090031.

Campbell, Angus, Philip Converse, Warren Miller and Donald Stokes. 1960. The American Voter. New York: Wiley.

Della Vigna, Stefano and Ethan Kaplan. 2003. "The Fox News Effect: Media Bias and Voting," Manuscript, Berkeley, California, March 30. elsa. berkeley .edu/ sdellavi/wp/foxvote0603-30.pdf.

Feltus, Will. 2009. “Cable News Bias? Audiences Say 'Yes'.” National Media Research, Planning, and Placement. October 29. nmrpp.com/CableNewsBiasAudiences.pdf.

Gentzkow, Matthew and Jesse M. Shapiro. 2010. "Ideological Segregation Online and Offline.” NBER Working Paper 15916. www.nber.org/papers/w15916.pdf.

Hamilton, James T. 2003. All the News That's Fit to Sell: How the Market Transforms Information into News. Princeton: Princeton University Press.

Hindman, Matthew. 2007. The Myth of Digital Democracy. Princeton: Princeton University Press.

Holsti, Ole R. 2004. Public Opinion and American Foreign Policy. Ann Arbor: University of Michigan Press.

Jacobson, Gary C. 2006. A Divider, Not a Uniter: George W. Bush and the American People. New York: Pearson Longman.

Jacobson, Gary C. 2007. "The War, the President, and the 2006 Midterm Congressional Elections." Paper presented at the annual meeting of the Midwest Political Science Association, Chicago, Illinois, April 12-15. 
Jones, Jeffrey. 2009. "State of the States: Political Party Affiliation.” Gallup, January 28. www.gallup.com/poll/114016/state-states-political-party-affiliation.aspx.

Kernell, Samuel and Laurie L. Rice. 2010. "Cable and Partisan Polarization of the President's Audience.” Unpublished manuscript, University of California, San Diego.

Kull, Steven, Clay Ramsay, and Evan Lewis. 2003. "Misperceptions, the Media, and the Iraq War," Political Science Quarterly 118 (4): 569-598.

Maugh, Thomas H. 2009. "Beck and Limbaugh Weigh in on Swine Flu." Booster Shots, LA Times, October 8. latimesblogs.latimes.com/booster_shots/2009/10/the-folks-whopublicly-said-they-would-rather-see-the-us-go-down-the-toilet-in-the-current-recessionrather-than-see-a-demo.html.

Lynd, Robert and Helen Lynd. 1929. Middletown: A Study in Contemporary American Culture. New York: Harcourt, Brace, and Company.

Media Matters for America. 2010. "Asman Responds to Surplus of H1N1 Vaccine by Fearmongering Over Danger of Vaccines.” July 1. mediamatters.org/mmtv/201007010074.

Page, Benjamin I. and Marshall M. Bouton. 2006. The Foreign Policy Dis*Connect: What Americans WANT from our Leaders but DON'T GET. Chicago: University of Chicago Press.

Parker-Pope, Tara. 2009. “Bill Maher vs. the Flu Vaccine.” Well Blog, New York Times, October 13.

Pew Project for Excellence in Journalism. 2009. "The State of the News Media 2009." www.stateofthemedia.org/2009.

Pew Project for Excellence in Journalism. 2010. "The State of the News Media 2010.” 
Www.stateofthemedia.org/2010.

Pew Research Center for the People and the Press. 2008. "News Consumption and Believability Study." August 17. people-press.org/reports/pdf/444.pdf.

Pew Research Center for the People and the Press. 2011. "Internet Gains on Television as Public's Main News Source.” January 4. people-press.org/reports/pdf/689.pdf.

Prior, Markus. 2007. Post-Broadcast Democracy: How Media Choice Increases Inequality in Political Involvement and Polarizes Elections. Cambridge, NY: Cambridge University Press.

San Antonio Express-News. 2009. “Cornyn Rips White House Over H1N1 Vaccine.” November 5. www.mysanantonio.com/default/article/Cornyn-rips-White-House-over-H1N1vaccine-843346.php.

Schlesinger, Robert. 2009a. "Whether to Get the H1N1 Vaccine." Thomas Jefferson Street Blog, U.S. News \& World Report, October 15. www.usnews.com/opinion/blogs/robertschlesinger/2009/10/15/whether-to-get-the-h1n1-vaccine.

Schlesinger, Robert. 2009b. "Democrats More Likely to Get the H1N1 Vaccine Than Republicans.” Thomas Jefferson Street Blog, U.S. News \& World Report, October 16. www.usnews.com/opinion/blogs/robert-schlesinger/2009/10/16/democrats-more-likelyto-get-h1n1-vaccine-than-republicans-2.

Schudson, Michael. 1981. Discovering the News: A Social History of American Newspapers. New York: Basic Books.

Sunstein, Cass. 2007. Republic.com 2.0. Princeton: Princeton University Press.

Thrush, Glenn. 2009. "Republican Doctors Question Virus Vaccine.” Politico, May 7. www.politico.com/news/stories/0509/22205.html. 
TABLE 1A. Correlates of Swine Flu Vaccination, by State (Part 1)

Newspaper Slant

Unemployment (9/09)

\% Black

\% Hispanic

H1N1 Cases per capita

Congressional Delegation Slant

Rep-Dem Registration Gap

Voted Obama 2008

\% Child Deaths 2009

Infant Death Rate 2004

\% Adults with Flu Vaccination 2009

\% Child Immunization 2009

Constant

Observations

R-squared

Robust standard errors in parentheses

$* * * p<0.001, * * p<0.01, * p<0.05, \wedge p<0.10$

\begin{tabular}{|c|c|c|c|c|c|c|}
\hline (1) & (2) & (3) & (4) & (5) & (6) & (7) \\
\hline$-0.981 *$ & $-0.760^{\wedge}$ & $-0.799^{\wedge}$ & $-1.002^{*}$ & $-0.666^{\wedge}$ & $-0.993 *$ & $-0.913^{*}$ \\
\hline$(0.42)$ & (0.43) & (0.46) & (0.43) & (0.34) & (0.42) & $(0.42)$ \\
\hline$-1.044 * * *$ & $-1.031 * * *$ & $-1.102 * * *$ & $-1.074 * * *$ & $-0.686^{\wedge}$ & $-1.058 * * *$ & $-1.046 * * *$ \\
\hline$(0.28)$ & $(0.28)$ & (0.29) & $(0.27)$ & (0.35) & (0.30) & (0.28) \\
\hline$-0.508 * * *$ & $-0.459 * * *$ & $-0.447^{* *}$ & $-0.504 * * *$ & $-0.429 * * *$ & $-0.537 * *$ & $-0.474 * * *$ \\
\hline$(0.12)$ & $(0.12)$ & (0.14) & (0.12) & (0.098) & (0.19) & $(0.13)$ \\
\hline$-0.115^{\wedge}$ & $-0.112^{\wedge}$ & $-0.126^{*}$ & $-0.111^{\wedge}$ & -0.076 & -0.107 & $-0.115^{\wedge}$ \\
\hline (0.059) & (0.058) & $(0.052)$ & (0.060) & (0.061) & (0.065) & (0.061) \\
\hline 0.0105 & 0.009 & 0.010 & 0.010 & 0.007 & 0.010 & 0.0113 \\
\hline (0.011) & $(0.012)$ & (0.013) & (0.012) & (0.011) & -0.011 & (0.012) \\
\hline$-0.171^{*}$ & -0.125 & -0.134 & $-0.170^{*}$ & $-0.183^{*}$ & $-0.179 *$ & $-0.153^{\wedge}$ \\
\hline \multirow[t]{12}{*}{ (0.077) } & (0.076) & $(0.081)$ & (0.078) & (0.070) & (0.085) & $(0.090)$ \\
\hline & $0.001^{\wedge}$ & & & & & \\
\hline & -0.0004 & & & & & \\
\hline & & $\begin{array}{c}0.023 \\
(0.014)\end{array}$ & & & & \\
\hline & & & & & & -0.001 \\
\hline & & & & & & -0.002 \\
\hline & & & & & 0.002 & \\
\hline & & & & & -0.01 & \\
\hline & & & & $0.475^{\wedge}$ & & \\
\hline & & & & -0.24 & & \\
\hline & & & -0.037 & & & \\
\hline & & & -0.11 & & & \\
\hline $0.954 * * *$ & $0.811 * * *$ & $0.836 * * *$ & $0.992 * * *$ & 0.436 & $0.952 * * *$ & $0.925^{* * *}$ \\
\hline$(0.20)$ & $(0.21)$ & $(0.23)$ & (0.25) & (0.28) & (0.20) & $(0.20)$ \\
\hline 50 & 50 & 50 & 50 & 50 & 50 & 50 \\
\hline 0.60 & 0.61 & 0.62 & 0.60 & 0.64 & 0.60 & 0.60 \\
\hline
\end{tabular}


TABLE 1B. Correlates of Swine Flu Vaccination, by State (Part II)

\begin{tabular}{|c|c|c|c|c|c|c|}
\hline & $(8)$ & (9) & $(10)$ & $(11)$ & $(12)$ & $(13)$ \\
\hline \multirow[t]{2}{*}{ Newspaper Slant } & $-1.002^{*}$ & $-0.991^{*}$ & $-0.961^{*}$ & $-0.894^{*}$ & $-0.934^{*}$ & $-0.990 *$ \\
\hline & $(0.43)$ & $(0.42)$ & $(0.44)$ & $(0.40)$ & $(0.42)$ & -0.440 \\
\hline \multirow[t]{2}{*}{ Unemployment (9/09) } & $-1.071 * *$ & $-1.032 * *$ & $-1.025 * *$ & $-1.029 * * *$ & $-1.025 * * *$ & $-1.053^{* *}$ \\
\hline & $(0.31)$ & $(0.30)$ & $(0.29)$ & $(0.29)$ & $(0.28)$ & $(0.31)$ \\
\hline \multirow[t]{2}{*}{$\%$ Black } & $-0.520 * * *$ & $-0.507^{* * *}$ & $-0.500 * * *$ & $-0.495 * * *$ & $-0.498 * * *$ & $-0.510 * * *$ \\
\hline & $(0.14)$ & $(0.12)$ & $(0.13)$ & $(0.12)$ & $(0.12)$ & -0.130 \\
\hline \multirow[t]{2}{*}{ \% Hispanic } & $-0.120^{\wedge}$ & -0.108 & $-0.116^{\wedge}$ & $-0.103^{\wedge}$ & $-0.104^{\wedge}$ & $-0.114^{\wedge}$ \\
\hline & $(0.066)$ & $(0.071)$ & $(0.060)$ & $(0.052)$ & $(0.060)$ & $(0.060)$ \\
\hline \multirow[t]{2}{*}{ H1N1 Cases per capita } & 0.010 & 0.0102 & 0.0103 & 0.0101 & 0.0108 & 0.0106 \\
\hline & $(0.011)$ & $(0.011)$ & $(0.012)$ & $(0.011)$ & $(0.012)$ & $(0.011)$ \\
\hline \multirow[t]{2}{*}{ Congressional Delegation Slant } & $-0.172^{*}$ & $-0.174^{*}$ & $-0.169 *$ & $-0.166^{*}$ & $-0.157^{\wedge}$ & $-0.172 *$ \\
\hline & $(0.077)$ & $(0.078)$ & $(0.078)$ & $(0.074)$ & $(0.081)$ & $(0.077)$ \\
\hline \multicolumn{7}{|l|}{ Rep-Dem Registration Gap } \\
\hline \multicolumn{7}{|l|}{ Voted Obama 2008} \\
\hline \multirow[t]{2}{*}{ GDP per capita 2009} & & & & & & -0.0000001 \\
\hline & & & & & & -0.000001 \\
\hline \multirow[t]{2}{*}{ Health Expenditure per capita 2004} & & & & & 0.000004 & \\
\hline & & & & & -0.000004 & \\
\hline \multirow[t]{2}{*}{ Medicaid Spending per capita 2008} & & & & 0.00000004 & & \\
\hline & & & & -0.00000003 & & \\
\hline \multirow[t]{2}{*}{ Median Income 2007} & & & 0.0000002 & & & \\
\hline & & & -0.000001 & & & \\
\hline \multirow[t]{2}{*}{ \% Urban Population } & & -0.008 & & & & \\
\hline & & $(0.044)$ & & & & \\
\hline \multirow[t]{2}{*}{ \% Living in Poverty 2009} & 0.036 & & & & & \\
\hline & -0.14 & & & & & \\
\hline \multirow[t]{2}{*}{ Constant } & $0.956 * * *$ & $0.965^{* * *}$ & $0.929 * * *$ & $0.878 * * *$ & $0.898 * * *$ & $0.964 * * *$ \\
\hline & $(0.20)$ & $(0.20)$ & $(0.23)$ & $(0.20)$ & $(0.20)$ & $(0.24)$ \\
\hline Observations & 50 & 50 & 50 & 50 & 50 & 50 \\
\hline R-squared & 0.60 & 0.60 & 0.60 & 0.61 & 0.60 & 0.60 \\
\hline
\end{tabular}

Robust standard errors in parentheses

*** $p<0.001, * * p<0.01, * p<0.05, \wedge p<0.10$ 


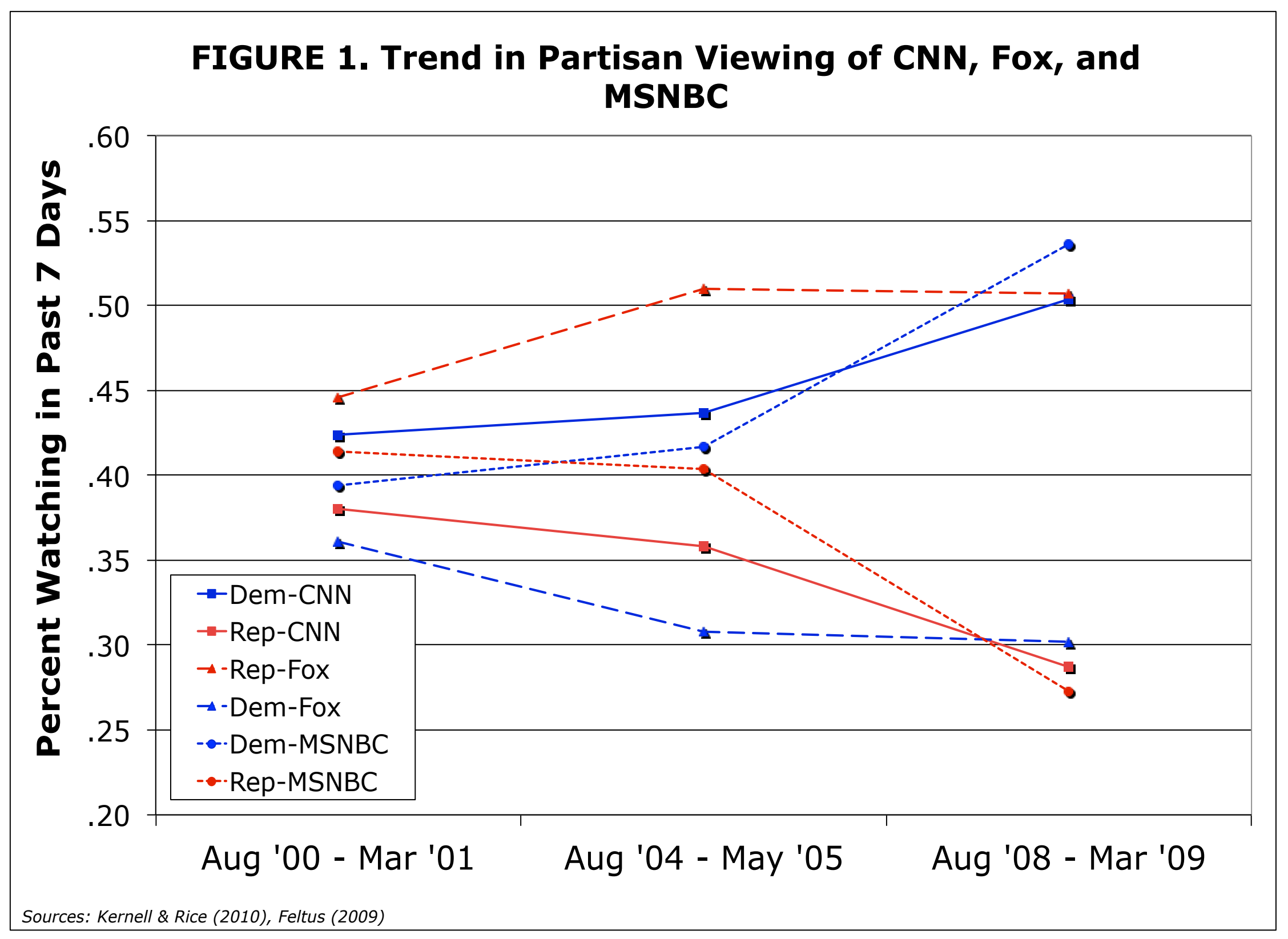




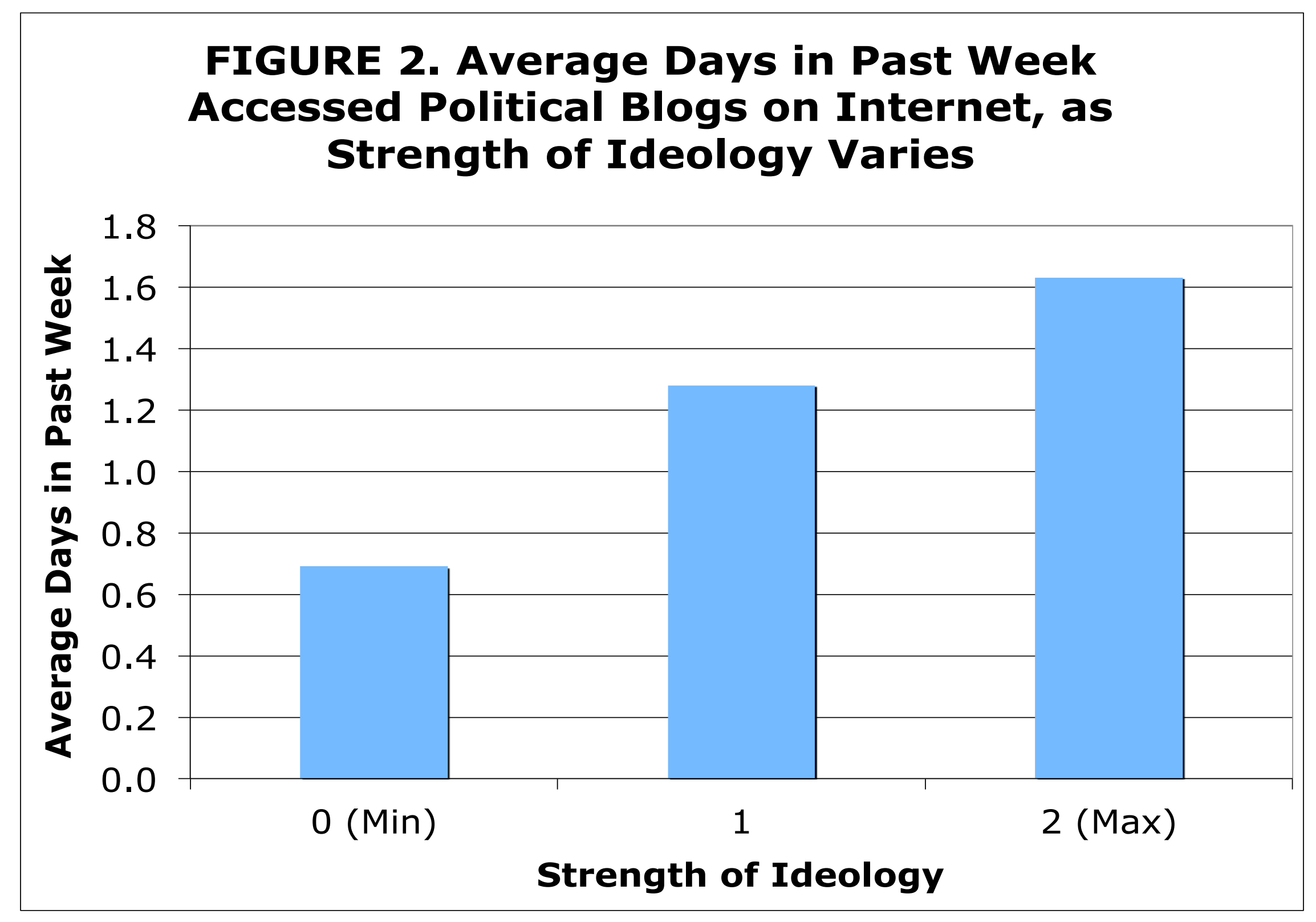




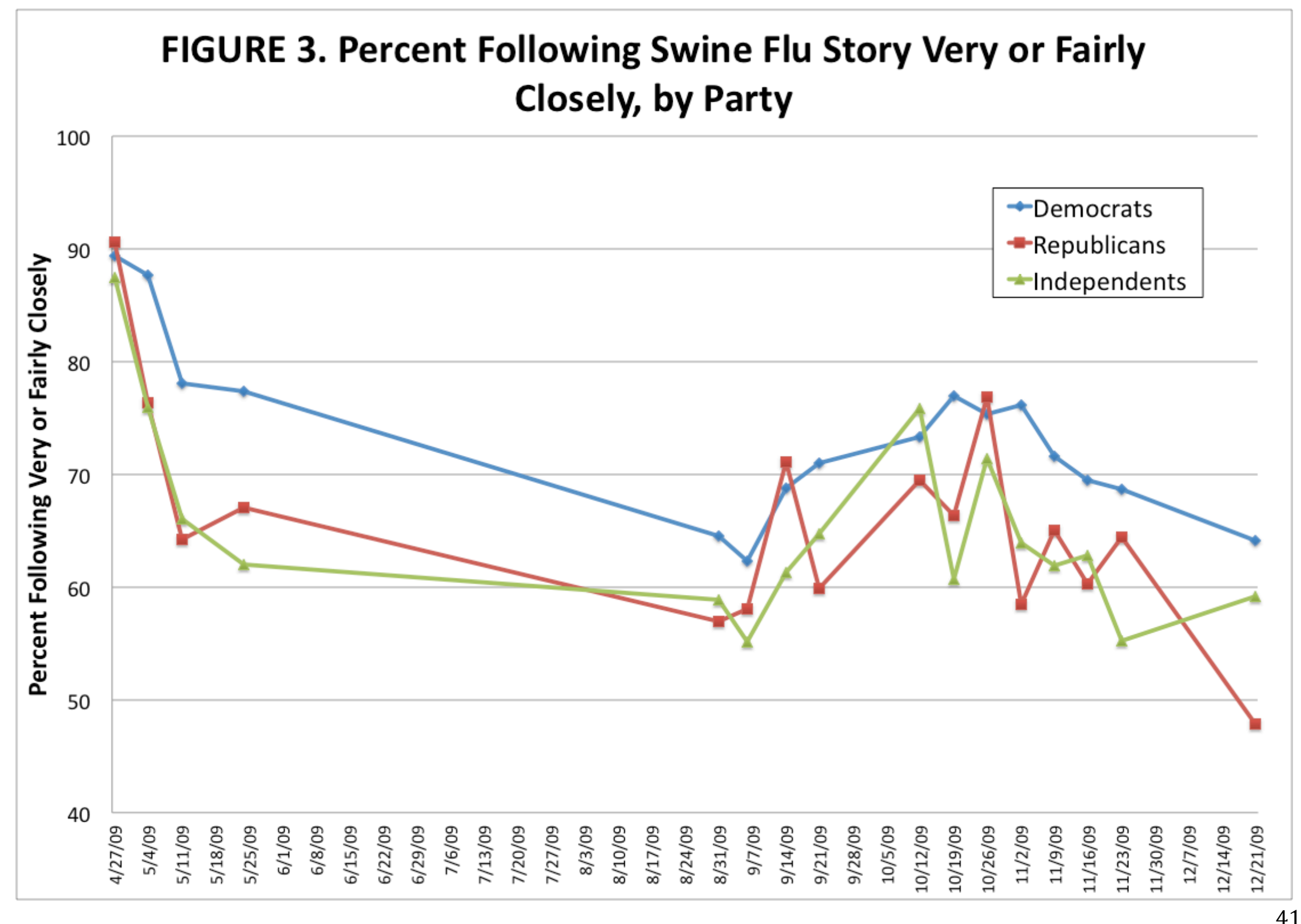

